\title{
PROTEÇÃO DOS ACIONISTAS MINORITÁRIOS NAS SOCIEDADES POR AÇÕES DE CAPITAL ABERTO: PANORAMA DAS PRINCIPAIS MEDIDAS ADMINISTRATIVAS E JUDICIAIS
}

\section{PROTECT OF MINORITY SHAREHOLDERS IN STOCK EXCHANGE COMPANIES MARKET: OVERVIEW OF THE JUDICIAL AND ADMINISTRATIVE PROCEDURES}

\author{
Arthur Giovanardi Dozza ${ }^{1}$ \\ Especialista em Direito Corporativo
}

Faculdade de Direito Tributário - Porto Alegre - Rio Grande do Sul (RS) - Brasil

RESUMO: A atividade empresarial é uma das maiores fontes de enriquecimento de um país, gerando, além de emprego e tributos, lucro para seus acionistas. Por isto, se mostra indispensável um estudo mais aprofundando dos instrumentos que possam vir a ser utilizados pelos acionistas minoritários, já que estão sempre contando com a benevolência dos interesses do grupo controlador. Serão tratadas as medidas administrativas e judiciais que o acionista minoritário terá o direito de valer-se no caso de ocorrência de ilegalidade ou injustiça ou caso não esteja satisfeito com alguma medida que seja tomada para o prejudicar indiretamente. Há, sem dúvidas, interesse notório na matéria, já que a sociedade por ações aceita qualquer um que esteja interessado em investir suas economias em ações de companhias abertas deverá saber. Ressalva-se que não há o intuito de esgotar o assunto sobre o tema. 0 objetivo é o de analisar, em tópicos, as peculiaridades dos instrumentos mais utilizados pelos acionistas minoritários na busca de equilíbrio quando da ocorrência da violação de seus direitos.

PALAVRAS-CHAVE: acionista minoritário; instrumentos administrativos; instrumentos judiciais.

\footnotetext{
${ }^{1}$ Graduado em Direito e Pós Graduado em Direito Corporativo pelo LLM da Faculdade Brasileira de Tributação - ProReitoria de Pós graduação Lato Sensu em Direito em parceria com o Instituto Brasileiro de Mercado de Capitais - IBMEC - realizado nas dependências do Instituto Nacional de Estudos Jurídicos e Empresariais em Porto Alegre, no Rio Grande do Sul. $\mathrm{O}$ artigo insere-se na Linha Editorial da Revista: Sociedade, Empresa e Sustentabilidade. Advogado. E-mail: arthurgdo@hotmail.com
} 
ABSTRACT: The business activity is a major source of enrichment of a country, generating, in addition to employment and taxes, profit for their shareholders. Therefore, it shows a more essential deepening of instruments that minority shareholders may use, since they are always relying on the benevolence of the interests of the controlling group. Will address both the administrative and judicial measures that the minority shareholders have the right to assert in the event of wrong or if you are dissatisfied with any action to take for the harm. There are, no doubt, notorious interest in the matter, since the corporation accepts almost every type of person as a shareholder, being a study without intention to exhaust the subject, however, anyone who is interested in investing their savings in stocks public companies should know. Therefore, the relevance of this theme is to analyze, on topics, the peculiarities of the most used by the minority in finding balance when the occurrence of the violation of their rights.

KEYWORDS: minority shareholder; administrative instruments; judicial instruments.

\section{Introdução}

O investimento em sociedade de capital aberto é uma das grandes alternativas de geração de lucros. Estas sociedades, em sua grande maioria, geridas por um grupo de controle ou um acionista majoritário, que acabam por impor somente suas próprias vontades, deixando os minoritários a mercê destes fatores, restando a eles somente a utilização de alguns mecanismos para obtenção de um equilíbrio nesta relação.

A atividade empresarial é uma das maiores fontes de enriquecimento de um país, gerando, além de emprego e tributos, lucro para seus acionistas. Por isto, se mostra indispensável um estudo mais aprofundando dos instrumentos que possam vir a ser utilizados pelos acionistas minoritários, já que estão sempre contando com a benevolência dos interesses do grupo controlador. Justifica-se este artigo por ser de fundamental importância a compreensão dos mecanismos que os acionistas minoritários dispõem na busca de proteção face aos anseios dos acionistas majoritários, preservando assim seus interesses.

O objetivo geral deste estudo está na análise dos principais instrumentos administrativos e judiciais disponíveis aos acionistas minoritários, analisando, na 
modalidade administrativa o I) direito de recesso; II) o direito ao tag along no caso de alienação do controle; III) a participação dos acionistas minoritários e preferencialistas na composição do conselho de administração; e IV) na participação dos acionistas minoritários e preferencialistas na composição do conselho fiscal.

Serão tratados os temas das medidas administrativas e judiciais que o acionista minoritário terá o direito de valer-se no caso de ocorrência de injustiça ou caso não esteja satisfeito com alguma medida que seja tomada para o prejudicar. Há, sem dúvidas, interesse notório na matéria, já que a sociedade por ações aceita quase que todo o tipo de pessoa como acionista, sendo um estudo, sem intuito de esgotar o assunto, contudo, qualquer um que esteja interessado em investir suas economias em ações de companhias abertas deverá saber.

Portanto, em relação aos instrumentos judiciais serão analisados as: (I) medidas cautelares inominadas; (II) ações anulatórias de deliberações com pedido liminar de suspensão dos efeitos das deliberações; (III) ações de responsabilidade civil; e (IV) ação revocatória.

A metodologia que será utilizada no presente estudo é a revisão bibliográfica e a análise de casos pontuais, derivados dos Tribunais de Justiça brasileiros, de forma descritiva.

Assim, tem-se cumprido os objetivos propostos com a apresentação dos mecanismos de proteção, administrativos e judiciais, que poderão se utilizar os acionistas minoritários frente aos interesses dos acionistas majoritários.

\section{Acionistas Minoritários: aspectos gerais}

Na atualidade, a necessidade da dispersão das ações de emissão de uma empresa traz, junto com os novos investidores/acionistas, uma gama de interesses que, apesar de serem convergentes em alguns aspectos como os que se referem à constituição, à participação e ao objeto da sociedade, podem ser diferentes ou quanto às questões que se referem as decisões para o engrandecimento social ${ }^{2}$.

Detém o controle de uma sociedade anônima o acionista ou grupo de acionistas que tiver o poder de comandar a sociedade, elegendo seus administradores e determinando as linhas básicas de atuação desta.

2BORBA, José Edwaldo Tavares. Direito Societário. Rio de Janeiro: Renovar. 8. ed., 2009. p. 109. 
Logo, o titular das ações de uma sociedade por ações é o acionista, e como tal, é o principal interessado na busca dos resultados positivos para a empresa, nos termos do art. 106, da Lei 6.404/76.

Uma Sociedade Anônima, bem como uma Sociedade Limitada não poderá ter menos de dois acionistas, em regra, sendo possível, somente no caso de subsidiária integral, prevista no art. 251 da Lei 6.404/76.

Não existem restrições para que alguma pessoa física seja acionista, podendo ser, inclusive, um incapaz. Sua principal função é a de arcar com o preço de emissão das ações que vier a subscrever, integralizando o capital da empresa e fomentando seu desenvolvimento.

Ocorre que, estas sociedades por ações são, muitas vezes, geridas por um acionista ou por um grupo de acionistas controlador, detentores da maior parte das ações com direito a voto. Esse poder de controle ocorre na Assembléia Geral Ordinária. $\mathrm{O}$ controlador de uma S/A responde pelos atos que praticar de forma abusiva.

Sendo este voto o poder de escolha dos destinos que a empresa irá tomar, quem possuir sua maioria acabará por impor seus interesses. A Lei descreve as hipóteses em que se verifica o exercício abusivo do poder de controle (art. 117 da Lei 6.404/76). Ex.: Diretor que se aproveita do cargo para auferir vantagens pessoais.

De outro norte, o sócio que possui menos direito ao voto é chamado de Sócio Minoritário e não possui poder de controle na sociedade, ou seja, é aquele que não tem poder de mando, aquele indivíduo ou sociedade, que sozinho não pode determinar os rumos da sociedade anônima, como entidade empreendedora, determinando uma espécie de submissão à lei da maioria, regra incomum do direito privado $^{3}$.

\subsection{Dificuldades na prevalência do voto dos acionistas minoritá- rios perante os acionistas controladores.}

Dentro de uma sociedade por ações, dificilmente os acionistas se tornaram sócios pelos mesmos motivos, tendo, cada um, seus próprios interesses, em razão dos mais diversos tipos de pessoas que compõe o quadro societário.

${ }^{3}$ SCHIMIDT, Dominique. Les Droits de la Minorité dans la Societé Anonyme. Paris: Sirey. 1970. p. 21. 
Vivante afirmou que o grande problema dos sistemas anonimários é a chamada "tirania della maggioranza", acreditando somente ser viável este tipo de sociedade na medida em que sejam assegurados direitos e garantias, impondo limitações ao poder da maioria, sem imobilizá-la 4 .

Como é evidente que o Acionista Minoritário está sempre fragilizado em relação aos interesses do grupo de controle, foram criados alguns instrumentos administrativos com o intuito de equilibrar essa relação.

Estes instrumentos são encontrados, essencialmente, em duas fontes: a Lei $\mathrm{n}^{\circ}$ 6.404, de 15 de dezembro de 1976 e a regulamentação da Comissão de Valores Mobiliários (CVM).

Os interesses dos acionistas minoritários se multiplicam e se diversificam a:

[...] cada deliberação da assembleia geral, a cada novo negócio e, no caso da companhia de capital aberto, a cada pregão. Com efeito, a análise da sociedade anônima "por dentro", isto é, a partir da posição do poder de comando, não é geral, parte-se do pressuposto abstrato da igualdade de todos os acionistas, atuando como companheiros num negócio em comum. Com isso, o ângulo de visão do profissional do Direito acerca do mecanismo societário é totalmente falseado ${ }^{5}$.

Ora, este ângulo de visão falseada precisa ser substituída pela verossimilhança dos conflitos existentes no seio da companhia, o que é o objeto deste trabalho.

\section{Panorama Geral dos principais instrumentos administrativos ne- cessários à proteção dos acionistas minoritários}

Frente aos anseios dos majoritários, foram criados então mecanismos administrativos para que o Acionista Minoritário possa tentar obter algum nível de equilíbrio em sua relação com controladores.

Alguns instrumentos que serão objetos do presente estudo são o:

${ }^{4}$ VIVANTE, Cesare. Trattato di Diritto Commerciale. Milano: Casa Editrice Dottor Francisco Vallardi. 1904. p. 297. ${ }^{5}$ COMPARATO, Fábio Konder. 0 poder de controle na sociedade anônima. $3^{\text {a }}$ ed. rev., atual. e corr. Rio de Janeiro: Forense, 1983. Texto da contracapa. 
a) direito de recesso;

b) direito ao tag along no caso de alienação do controle;

c) participação dos acionistas minoritários e preferencialistas na composição do conselho de administração; e

d) participação dos acionistas minoritários e preferencialistas na composição do conselho fiscal.

Referidos mecanismos da agência reguladora são fundamentais na busca de equilíbrio e equidade entre todo o quadro de acionistas de uma sociedade, fornecendo segurança não somente aos que já estão inseridos neste quadro, mas também aos que eventualmente se interessarem em adquirir ações de uma determinada companhia,tendo a garantia de que não sofrerão abusos do grupo de controle ou acionista controlador.

\subsection{Direito de Recesso}

O direito de Recesso diz respeito aos acionistas Minoritários terem a possibilidade de requerer sua saída da sociedade por meio do reembolso do valor de suas ações pela companhia, sempre que determinadas deliberações forem aprovadas em assembleia.

Regulamentado pela lei 6.404/76, o Direito de Recesso foi estabelecido pelo legislador expressamente nos casos em que poderá ser exercido, bem como a forma do cálculo do valor das ações a ser reembolsado.

Conforme ensina Fábio Ulhoa, o acionista dissidente de determinadas deliberações da assembleia geral ou de companhia cujo controle foi desapropriado tem o direito de se retirar da sociedade, recebendo o reembolso de suas ações. A base para o cálculo do reembolso é o valor patrimonial das ações do acionista dissidente. Assim, o acionista que se retira terá direito de receber da sociedade, por cada ação que titulariza, a importância equivalente à divisão do patrimônio líquido da companhia pelo número de ações"6.

Pode ocorrer o direito de recesso, conforme o art. 136, inciso I, da Lei 6.404/76, se criadas novas ações preferenciais ou aumento de classe de ações preferenciais existentes,

${ }^{6}$ COELHO, Fábio Ulhoa. Manual de Direito Comercial. São Paulo: Saraiva. 2011. p.240. 
sem guardar proporção com as demais classes de ações preferenciais, salvo se já previstas ou autorizadas pelo estatuto.

Poderá, também, ser utilizado no caso de ocorrer alguma alteração nas preferências, vantagens e condições de resgate ou amortização de uma ou mais classes de ações preferenciais, ou criação de nova classe mais favorecida, conforme o art. 136, inciso II, da Lei 6.404/76.

A redução do dividendo obrigatório também está prevista na Lei 6.404/76 em seu art. 136, inciso III, bem como no caso de fusão da companhia, ou sua incorporação em outra, face o art. 136, inciso IV.

Outros casos em que poderá ocorrer o direito de recesso pelo minoritário são os seguintes:

a) participação em grupo de sociedades (art. 136, inciso V e 265 da Lei 6.404/76);

b) mudança do objeto social da companhia (art. 136, inciso VI, da Lei 6.404/76);

c) cisão da companhia (art. 136, inciso IX, da Lei 6.404/76);

d) transformação da companhia em outro tipo societário (art. 221 da Lei 6.404/76);

e) não abertura de capital da sociedade que resultar de uma operação de incorporação, fusão ou cisão envolvendo companhia aberta (art. 223, § $3^{\circ}$ e $\S 4^{\circ}$, da Lei 6.404/76);

f) desapropriação de ações representativas do controle acionário da companhia em funcionamento por pessoa jurídica de direito público (art. 236, par. único, da Lei 6.404/76);

g) incorporação de ações (art. 252, \$1 ${ }^{\circ}$, da Lei 6.404/76); e

h) aprovação ou ratificação da aquisição do controle de outra sociedade mercantil (art. 256, § $2^{\circ}$, da Lei 6.404/76).

Estas possibilidades acima expressas são direitos essenciais dos acionistas minoritários, e não poderão ser recusadas ou limitadas pela Assembleia Geral, bem como pelo estatuto social (art. 109, inciso V, da Lei 6.404/76).

\subsection{Direito ao Tag Along no Caso de Alienação do Controle}

Quando estiver sendo encaminhada uma alienação do controle de uma sociedade anônima, com base no artigo 254-A da Lei 6.404/76, o novo controlador 
será compelido a realizar oferta pública para adquirir as ações pertencentes aos acionistas minoritários titulares de ações com direito a voto.

Para evitar distorção, os acionistas minoritários devem condicionar o ingresso na sociedade à cláusula de saída conjunta, no estatuto ou em acordo de acionistas. Quando prevista esta cláusula, o controlador não pode vender suas ações isoladamente. Quer dizer, só poderá vendê-las a quem se comprometa a adquirir também as dos beneficiados pela cláusula. Viabiliza-se, deste modo, a distribuição do "prêmio de controle" entre os acionistas com direito de saída conjunta".

Essa possibilidade de o acionista minoritário alienar suas ações ao novo controlador é usualmente conhecida no mercado como o tag along, e, conforme da Instrução CVM n 361/2002, os destinatários desta aludida oferta pública por alienação do controle são apenas os minoritários titulares de ações com direito a voto pleno e permanente.

Assim, em regra, os acionistas preferenciais sem direito a voto ou com voto restrito não têm direito de demandar o novo controlador para que também adquira as ações por eles detidas.

Poderá ocorrer, contudo, a inclusão no estatuto social da companhia uma cláusula no sentido de estender expressamente o direito ao tag along também aos acionistas sem direito a voto, permitindo a venda das ações de sua propriedade na oferta pública por alienação do controle.

A regra para ocorrer o tag along não é só no momento em que o acionista majoritário ou grupo de controle vende diretamente suas ações controladoras para um terceiro, pois o artigo 254-A da Lei 6.404/86 deu novo sentido ao termo "alienação do controle acionário".

Assim, os acionistas minoritários poderão requerer também a realização de oferta pública quando ocorrer a alienação indireta do controle, ou seja, quando se aliena o controle da sociedade, ou também em alguma outra operação que tenha como resultado a mudança do controle acionário da companhia aberta, como no caso de transferência de valores mobiliários que poderão ser convertidos em ações com direito a voto e a cessão de direito de subscrição de ações com direito a voto.

Nestes casos, o valor a ser pago aos minoritários na oferta pública deve ser

${ }^{7}$ COELHO, 2011, op. cit, p. 245. 
correspondente a, no mínimo, $80 \%$ (oitenta por cento) do valor das ações dos acionistas do bloco de controle.

Contudo, conforme afirma Gorga, a reforma da legislação deveria ter estabelecido tag along de $100 \%$, porque tag along de $80 \%$ ainda permite possibilidade de considerável expropriação, incentivando os benefícios privados de controle a permanecer num patamar alto não desejável ${ }^{8}$.

\subsection{A Participação dos Acionistas Minoritários e Preferencialistas na Composição do Conselho de Administração}

Obrigatório nas Sociedades Anônimas conforme art. 138 , §§ $1^{\circ}$ e $2^{\circ}$ da Lei 6.404/76, o Conselho de Administração é um órgão colegiado, e sua função é a de decidir sobre determinados temas definidos em lei e no estatuto social.

As funções do Conselho de Administração são: a eleição dos diretores da companhia, escolha e destituição dos auditores independentes, orientação geral dos negócios e a prestação de garantias, pela companhia, a obrigações de terceiros, segundo o art. 142 da Lei 6.404/76.

Ocorre que, a partir de 31 de outubro de 2001, foram introduzidas respeitáveis modificações no processo eletivo do conselho de administração das Sociedades Anônimas, com a adição dos $\$ 4^{\circ}$ ao $\S 9^{\circ}$ ao artigo 141 da Lei 6.404/76.

Essas modificações têm por finalidade o aumento da representação dos acionistas minoritários no conselho de administração, podendo ser tanto por titulares de ações com direito a voto, como também os acionistas preferenciais sem direito a voto ou com restrição ao exercício desse direito.

Assim, sendo o voto múltiplo um instrumento que majora significativamente a probabilidade de minoritários obterem representatividade no conselho de administração, nada mais é do que um meio de se elevar a democracia nos órgãos deliberativos de uma companhia.

Regido pelo art. 141 e parágrafos da Lei 6.404/76, os detentores de ações ordinárias que representem no mínimo $10 \%$ do capital social tem o direito ao requerimento, na eleição dos membros do conselho, da utilização do voto múltiplo, mesmo que não exista essa possibilidade no contrato social da companhia.

${ }^{8}$ GORGA, Erica. A cultura brasileira como fator determinante na governança corporativa e no desenvolvimento do mercado de capitais. Revista de Administração - USP, São Paulo, v. 39, n. 4, 2004, p. 315. 
Se requerido o voto múltiplo, todas as outras ações estarão afetadas ao seu princípio, e não somente as que o solicitaram, obedecendo assim as suas regras particulares, e, também, terá o acionista o direito de concentrar seus votos em um único candidato ou os distribuir como bem entender.

Outras situações em que os acionistas minoritários podem nomear um membro do conselho de administração por intermédio do voto em separado são: com os a) titulares de ações com direito a voto de companhia aberta com,no mínimo15\% do total das ações votantes;2) os detentores de ações preferenciais (sem direito a voto), caso o estatuto social da companhia garanta o direito de eleger um assento; e os 3) titulares de ações preferenciais de companhia aberta com,pelo menos $10 \%$ do total de ações que não tenham exercido a opção do item 2 , fundamentados nos artigos 141 , parágrafo $4^{\circ}$, inciso I, artigo 18 da Lei 6.404/76 e no artigo 141 , parágrafo, $4^{\circ}$ inciso $\mathrm{II}$, respectivamente.

\subsection{Participação dos Acionistas Minoritários e Preferencialistas na Composição do Conselho Fiscal}

A eleição para o conselho fiscal de uma sociedade por ações pelos acionistas minoritários poderá ser realizada pela convocação de uma Assembleia Geral por, no mínimo, 5\% (cinco por cento) do capital votante, ou 5\% (cinco por cento) das ações sem direito a voto.

Essa Assembleia Geral terá por objetivo específico instalar um conselho fiscal, respeitando-se as regras do parágrafo $4^{\circ}$ do artigo 161 , e os acionistas minoritários e preferencialistas terão direito a eleger um membro do conselho fiscal e seu suplente, capacidade que renova o poder de fiscalização dos atos societários e aumenta a transparência da sociedade.

Conforme ensina GORGA, a medida representa um avanço, pois permite aos acionistas preferencialistas e minoritários, detentores de ações votantes, a indicação de um representante para monitorar e participar efetivamente da gestão da sociedade, fazendo com que esses grupos tenham acesso a informações acerca da condução dos negócios 9 .

${ }^{9}$ GORGA, 2004, p. 313. 


\subsection{0 voto múltiplo}

O processo de voto múltiplo, previsto no artigo 141 da Lei $6.404 / 76$, é um benefício legal atribuído aos acionistas minoritários de sociedades anônimas que detenham (em conjunto com outros acionistas, ou isoladamente) ao menos $5 \%$ do respectivo capital social, podendo ser utilizado exclusivamente para a eleição dos membros do Conselho de Administração da companhia, e ainda que não haja previsão estatutária a respeito.

Este direito deve ser requerido à companhia em até 48 horas antes da realização da assembléia geral pertinente, resulta na atribuição, a cada ação votante, de tantos votos quantos sejam os membros do Conselho a ser eleito, reconhecendo-se aos acionistas o direito de cumular seus votos num só candidato ou de distribuí-los entre vários candidatos.

O percentual de ações votantes necessário para requisição do processo é de $10 \%$, nas companhias fechadas, e varia de $5 \%$ a $10 \%$, nas companhias abertas, conforme o valor do seu capital social, adotando-se, para tanto, a tabela constante da Instrução $C V M n^{\circ} 165 / 91$, cujo artigo $1^{\circ}$ foi atualizado através da Instrução CVM n ${ }^{\circ} 282 / 98$.

Tal procedimento, mais conhecido no direito norte-americano, pode resultar em efetivo benefício aos acionistas minoritários, sendo conhecidos casos em que estes chegaram a eleger a maioria de um Conselho de Administração, em detrimento do acionista controlador, que podem se sujeitar as penas de configuração de infração administrativa grave, a qual sujeitaria a companhia e seus administradores às penalidades previstas no artigo 11 , incisos I a VI, da Lei ${ }^{\circ} 6.385 / 76$ (advertência, multa, e suspensão ou inabilitação para o exercício de cargo de administrador de companhia aberta).

\subsection{0 direito de preferência}

Na proporção do número de ações que possuírem, os acionistas terão preferência para a subscrição do aumento de capital, nos termos do art. 171, da Lei $6.404 / 76$.

Observa-se que se o capital for dividido em ações de diversas espécies ou classes e o aumento for feito por emissão de mais de uma espécie ou classe, observar-se-ão as seguintes normas: 
a) no caso de aumento, na mesma proporção, do número de ações de todas as espécies e classes existentes, cada acionista exercerá o direito de preferência sobre ações idênticas às de que for possuidor;

b) se as ações emitidas forem de espécies e classes existentes, mas importarem alteração das respectivas proporções no capital social, a preferência será exercida sobre ações de espécies e classes idênticas às de que forem possuidores os acionistas, somente se estendendo às demais se aquelas forem insuficientes para lhes assegurar, no capital aumentado, a mesma proporção que tinham no capital antes do aumento;

c) se houver emissão de ações de espécie ou classe diversa das existentes, cada acionista exercerá a preferência, na proporção do número de ações que possuir, sobre ações de todas as espécies e classes do aumento.

No aumento mediante capitalização de créditos ou subscrição em bens, será sempre assegurado aos acionistas o direito de preferência e, se for o caso, as importâncias por eles pagas serão entregues ao titular do crédito a ser capitalizado ou do bem a ser incorporado. E, os acionistas terão direito de preferência para subscrição das emissões de debêntures conversíveis em ações, bônus de subscrição e partes beneficiárias conversíveis em ações emitidas para alienação onerosa; mas na conversão desses títulos em ações, ou na outorga e no exercício de opção de compra de ações, não haverá direito de preferência.

Importante ressaltar que o estatuto ou a assembléia-geral fixará prazo de decadência, não inferior a 30 (trinta) dias, para o exercício do direito de preferência. $E$, no caso de usufruto e de fideicomisso, o direito de preferência, quando não exercido pelo acionista até 10 (dez) dias antes do vencimento do prazo, poderá sê-lo pelo usufrutuário ou fideicomissário.

Além disso, todo acionista poderá ceder seu direito de preferência. E, nas companhias abertas, o órgão que deliberar sobre a emissão mediante subscrição particular deverá dispor sobre as sobras de valores mobiliários não subscritos, podendo:

a) mandar vendê-las em bolsa, em benefício da companhia; ou

b) rateá-las, na proporção dos valores subscritos, entre os acionistas que tiverem pedido, no boletim ou lista de subscrição, reserva de sobras; nesse caso, a 
condição constará dos boletins e listas de subscrição e o saldo não rateado será vendido em bolsa, nos termos da alínea anterior.

\subsection{0 acordo de acionistas na modalidade defensiva}

Modesto Carvalhosa ${ }^{10}$ conceitua o acordo de acionistas, sob a perspectiva do art. 118 da Lei 6.404/76, como sendo "um contrato submetido às normas comuns de validade de todo negócio jurídico privado, concluído entre acionistas de uma mesma companhia, tendo por objetivo a regulação do exercício dos direitos referentes à suas ações, tanto no que se refere ao voto como à negociabilidade das mesmas."

Fábio Ulhoa Coelho ${ }^{11}$ menciona que o acordo de acionistas é instrumento criado pelo legislador e tem como função a estabilização de posições acionárias, podendo os acionistas, ao fazerem uso do acordo de acionistas, "contratar sobre quaisquer assuntos relativos aos interesses comuns que os unem, havendo, a rigor, um único tema excluído do campo da contratação válida: a venda de voto."

Muitas vezes, torna-se necessário que uma minoria organizada de acionistas se arranje em torno de um mesmo objetivo. Assim, o acordo de acionistas apresenta-se como um instrumento eficaz para a aglutinação dessa minoria, por meio de seus signatários, não detentores do poder de controle da companhia, procurem resguardar seus interesses em comum ${ }^{12}$.

0 acordo de acionista defensivo será constituído como instrumento de reunião da minoria, cuja vocação se circunscreve a dar organização jurídica aqueles acionistas não detentores do controle da companhia abeta que pretendam fazer prevalecer seus interesses diante do grupo controlador ${ }^{13}$.

Ressalva-se que, nem todo acordo de defesa terá como objeto o exercício do direito de voto de seus signatários. Casos existem em que a reunião dos minoritários em torno do acordo diz respeito a uma atuação que não em órgão colegiado da companhia ${ }^{14}$.

Cita-se também, como exemplo, a legitimidade aos acionistas que representem ao menos $5 \%$ do capital social para solicitar a exibição dos seus livros socie-

\footnotetext{
${ }^{10}$ CARVALHOSA, Modesto. Acordo de Acionistas, São Paulo: Editora Saraiva, 2011, p.9. ${ }^{11}$ COELHO, Fabio Ulhoa. Curso de Direito Comercial. Volume 2. 12. ed. São Paulo: Editora Saraiva, 2010, p. 315-316. ${ }^{12 B E R T O L D I, ~ M a r c e l o . ~ A c o r d o ~ d e ~ A c i o n i s t a s . ~ S a ̃ o ~ P a u l o: ~ R e v i s t a ~ d o s ~ T r i b u n a i s, ~ 2006, ~ p .86 . ~}$ ${ }^{13}$ BERTOLDI, 2006, p.86.

${ }^{14}$ BERTOLDI, 2006, p.87.
} 
tários. Enfim, "os acordos de defesa podem compor os interesses utisinguli dos minoritários, independentemente da classe ou espécie das ações possuídas pelos contratantes" ${ }^{15}$.

\section{Panorama Geral dos principais instrumentos judiciais necessários à proteção dos acionistas minoritários}

Além das já citadas medidas administrativas das quais os acionistas minoritários podem se utilizar para buscar algum tipo de igualdade nos momentos em que for lesado, existem também as medidas judiciais, instrumentos estes utilizados para que o julgador consiga buscar e interpretar algum tipo de proteção que não estejam previstos ou abarcados pelos instrumentos administrativos, fazendo uso da interpretação do órgão jurisdicional, no sentido de buscar a solução mais justa ao caso concreto.

\subsection{As Medidas Cautelares Inominadas}

O acionista minoritário, quando se sentir prejudicado por algum motivo e não conseguir acionar os responsáveis pela esfera administrativa, poderá recorrer à medida cautelar inominada.

Por se tratar de uma medida cautelar, ela poderá cumular com pedido de liminar, não existindo um padrão para o ingresso deste tipo de ação, podendo ser desde uma ação principal ou mesmo para assegurar algum direito que será objeto de ação posterior.

Contudo, por se tratar de uma ferramenta jurisdicional, serão apreciados fatos e provas, ficando o minoritário sujeito à interpretação da norma pelo judiciário, como por exemplo, no caso da sociedade por ações OGX, empresa sob a gestão do empresário Eike Batista:

A juíza em exercício da $5^{\text {a }}$ Vara Empresarial da Capital, Maria Isabel Paes Gonçalves, negou nesta quinta-feira, dia 11, a liminar (medida cautelar inominada) movida pelo acionista minoritário da empresa OGX Petróleo e Gás Participações, Marcio de Melo Lobo, que pedia o bloqueio dos bens e direitos, além de

${ }^{15}$ Idem. 
vedar a quitação das dívidas da companhia e do empresário Eike Batista.

Em sua decisão, a magistrada afirma que o bloqueio dos bens da OGX é inadequado.

"No momento, convenci-me de que a indisponibilidade dos bens da sociedade não se mostra adequada, vez que poderá gerar mais problemas do que solução", ressalta a juíza.

Na mesma decisão, a magistrada relata que não há justificativa para tornar indisponíveis os bens de Eike Batista. "No que concerne ao segundo requerido, Eike Batista, não vislumbro a imputação de conduta na condição de administrador da primeira requerida, OGX, que justifique a indisponibilidade dos seus bens. Sendo certo, em linhas gerais, que o administrador responde pessoalmente pelos resultados negativos da empresa administrada aos quais der causa. $\mathrm{E}$, do exame perfunctório dos fatos, não se extrai a presença dos pressupostos autorizadores à concessão da medida postulada", decidiu a juíza.

A magistrada ressalta que, através de matérias jornalísticas anexadas aos autos, a OGX atravessa situação econômico-financeira difícil e mostra a necessidade de os administradores adotarem medidas para superar as dificuldades existentes.

Processo $n^{\circ}$ 0236942-88.2013.8.19.000116

Como se pode notar, a intenção do acionista minoritário de bloquear os bens da requerida restou prejudicada frente aos interesses da sociedade, pois este tipo de interpretação fica à critério do julgador, que analisará os fatos, provas e com base em sua convicção decidirá o que é justo para cada uma das partes.

\subsection{As ações Anulatórias de Deliberações com Pedido Liminar de Suspensão dos Efeitos das Deliberações}

Além das medidas cautelares inominadas, estão também ao alcance dos acionistas minoritários as ações anulatórias de deliberação com pedido liminar de suspensão dos efeitos das deliberações.

Esse tipo de ação, diferentemente das cautelares inominadas, busca alterar os efeitos de alguma modificação no contrato social realizada de maneira a prejudicar o minoritário, como, por exemplo, o presente caso:

16BRASIL. Poder Judiciário do Estado do Rio de Janeiro. Assessoria de Imprensa. Rio de Janeiro. Publicada em 11 jul.2013. Disponível em: <http://www.tjrj.jus.br/web/guest/home/-/noticias/visualizar/130708>. Acesso em 14 set. 2013. 
Tutela antecipada. Ação anulatória de deliberação societária e alteração contratual de sociedade empresarial. Pedido liminar inaudita altera pars para suspender os efeitos de alteração do Contrato Social de sociedade limitada e reintegrar o autor em seu quadro societário. Fundamento na ilegalidade da deliberação. Concessão em primeira instância. Revogação, devido à existência de controvérsia a respeito da invalidade da exclusão do sócio e à concordância dos litigantes no tocante à inexistência de affectio societatis. Restabelecimento dos efeitos da última alteração contratual, onde deliberada a medida de exclusão do sócio. Agravo de instrumento provido ${ }^{17}$.

No caso supra citado vemos que em primeira instância foi concedido um pedido liminar inaudita altera pars no sentido de suspender os efeitos de uma alteração no contrato social, e mais, reintegrar o autor ao quadro societário da companhia.

Nota-se também que, a segurança gerada nas ações judiciais podem ser provisórias, já que o entendimento de juízos de primeira instância podem não ser os mesmos dos tribunais recursais, tornando a segurança aos minoritários no âmbito judicial menos precisa do que no administrativo.

\subsection{As Ações de Responsabilidade Civil}

Os acionistas minoritários poderão ainda, na verificação de algum ato ilícito praticado pelo controlador, ingressar com uma ação de responsabilidade civil visando anular alguma deliberação ou buscar a reparação civil pelos danos causados.

Referidas ações poderão ainda ser cumuladas, tendo, contudo, prazos prescricionais diferentes, sendo de dois anos para ingresso da ação de nulidade e de três anos para ingresso da ação de responsabilidade civil.

De outro norte, caso estivesse o controlador agindo na qualidade de administrador, poderia responder por perdas e danos solidariamente com os demais administradores e fiscais que tenham com ele formado um conluio, negligenciaram

\footnotetext{
${ }^{17}$ BRASIL. Tribunal de Justiça do Estado de São Paulo. Agravo de Instrumento n 1451734120128260000 -SP (014517341.2012.8.26.0000). Agravante: CONSTRUTORA CONSTERP LTDA. Agravado: ANTONIO AMERICOTAMAROZZI. Relator: José Reynaldo. São Paulo, 04 de dezembro de 2012. Lex: Disponível em: <http: //tj-sp.jusbrasil.com.br/jurisprudencia/22796572/ agravo-de-instrumento-ag-1451734120128260000-sp-0145173-4120128260000-tjsp>. Acesso em: 16 set. 2013.
} 
o ilícito sabendo de sua existência ou também deixaram de agir para evitar sua prática, conforme previsão do artigo 158 da Lei 6.404/76.

As presentes ações em estudo poderão ainda ser discutidas em sede de arbitragem, tendo em vista o disposto no art. 109 da Lei 6.404/76, que permite a utilização do juízo arbitral para resolver as questões que envolverem acionista controlador, acionistas minoritários, companhia e os outros acionistas.

Em regra geral, o administrador ou fiscal irão se sujeitar à arbitragem somente com sua prévia concordância, excetuadas as ocasiões que autorizem a imediata sujeição do rito arbitral.

\subsection{Ação Revocatória}

A ação revocatória, quando no âmbito empresarial, mais precisamente nos casos de falência, recebe o nome de ação revocatória falimentar ou simplesmente ação revocatória, que teve sua terminologia analisada por Nelson Abrão da seguinte forma:

Bem de ver, contudo, que os autores que identificam as expressões "pauliana" e "revocatória" não o fazem na acepção que esta última adquiriu como procedimento específico no campo do direito falimentar, mas num sentido lato de via processual destinada a desconstituir, em relação à massa, o ato praticado pelo devedor insolvente. À medida que se passou a reservar, com exclusividade, a revocatória ao âmbito falimentar, revelou ela acentuada diferenciação em relação à pauliana ${ }^{18}$.

A ação revocatória falimentar está disposta nas situações em que ocorre um processo de falência, e dependerá da sentença que declarar o estado falimentar para ter cabimento.

Seu principal objetivo é tornar ineficazes os atos em relação à massa falida, e pode possuir duas espécies: a) a ação revocatória por ineficácia de ato e; b) ação revocatória por revogação de ato. Ambas estão previstas nos artigos 129 e 130 da Lei $11.101 / 05$, respectivamente.

${ }^{18}$ ABRÃO, Nelson. Da ação revocatória. São Paulo: Universitária de Direito, 1997, p. 27. 
Nos casos de ação revocatória por ineficácia de ato, disposto no art. 129, ocorre a declaração da ineficácia de um ato em relação à massa, ato este que jamais foi eficaz. Trata-se portando de uma ineficácia objetiva, imposta por Lei, declarando os efeitos ex tunc.

Já nos casos de ação revocatória por revogação de ato, também ocorre a declaração da ineficácia de um ato em relação à massa, só que, neste caso, o ato foi eficaz, porque com aparência conforme o direito, como ocorre costumeiramente nas fraudes. Neste caso a ineficácia terá efeitos ex nunc, por ter sido revogado o ato.

A ação revocatória falimentar possui distinção em relação à ação pauliana civil por ser especializada. Contudo, ambas pretendem restringira fraude contra credores e possuem prazo decadencial para interposição.

Ambas ações, revocatória e pauliana civil geram benfeitorias aos credores em concurso. Contudo, no caso da revocatória se conserva a validade do ato a terceiros, e na ação pauliana civil o ato deixa de ser válido para terceiros e inclusive para a falida.

Se antes da decretação da falência a sociedade vier a sofrer uma ação pauliana, e, após este fato falir, pela atuação da vis attractiva do juízo falimentar, deverá ser a ação pauliana recebida pelo juízo falimentar como revocatória, conforme o art. 244 do CPC, pois se trata de uma matéria especial, sendo o prazo decadencial para ambas, para que não haja dúvida em relação ao prazo que a lei estabelece para aceitação destas.

\section{Considerações Finais}

Apresentam-se conflitos que impulsionaram o legislador a criar mecanismos jurídicos de tutela do acionista minoritário, tais como o voto múltiplo, a eleição em separado, o direito de preferência, o direito de recesso, o direito de saída conjunta e os acordos de acionistas da modalidade defensiva.

Constata-se que os conflitos que têm conduzido à adoção das melhores práticas de governança corporativa como o tag along de cem por cento, característico do Novo Mercado.

A Superintendência de Relações com Empresas (SEP) da CVM divulgou em 28/02/2013, o Ofício-Circular CVM/SEP/N ${ }^{\circ} 01 / 2013$. O documento tem o objetivo de orientar os emissores, particularmente, sobre as interpretações dadas pelo 
Colegiado da CVM e pela área técnica referente a aspectos relevantes da legislação e regulamentação societária que devem ser considerados pela companhia quando da realização de operações que afetem os acionistas minoritários.

Com esta iniciativa, a SEP pretendeu fomentar as melhores práticas de governança corporativa, visando à transparência e à equidade no relacionamento com os investidores e o mercado, bem como minimizar eventuais desvios e, consequentemente, reduzir a necessidade de formulação de exigências e aplicação de penalidades.

A SEP estabelece as novas orientações, principalmente, sobre os seguintes assuntos:

a) participação de acionistas nos processos de eleição em separado de membros do conselho fiscal e do conselho de administração previstos artigos 161, parágrafo $4^{\circ}$, letra "a", e no artigo 240 da Lei n ${ }^{\circ} 6.404 / 76$, bem como no artigo 141, parágrafos $4^{\circ}$ e $5^{\circ}$, e no artigo 239 dessa mesma Lei; e

b) divulgação pela companhia de pedidos de adoção do processo de voto múltiplo que atendam aos requisitos estabelecidos na Lei e na regulamentação específica.

Estas práticas ratificam que devem ser observados os direito dos minoritários e que estes podem se defender administrativamente.

Ademais, por todo o exposto no presente trabalho pode-se concluir que os instrumento para a proteção dos acionistas minoritários são de fundamental importância no ambiente socioeconômico das companhias abertas, já que, além de seu caráter de proteção, possui também um caráter de estímulo ao empreendimento, já que passa ao minoritário a sensação de segurança para investir.

Em relação à comparação entre os instrumentos administrativos e judiciais de proteção, constatou-se que a eficiência dos administrativos é muito maior, pois, bastando o cumprimento de alguns requisitos básicos, eles poderão ser acionados e mais rapidamente executados pelo acionista.

Já em relação aos instrumentos judiciais, ficou demonstrado que muitas vezes os assuntos são bastante complicados, pois temos, de um lado, uma pessoa física ou jurídica que é uma pequena investidora, e de outro a grande empresa, geradora de empregos e tributos. Assim, esta leva vantagem sob aquela, pois o fator social da companhia é muito importante, sobrepujando os interesses individuais. 
Importante ressaltar que, apesar de ser menos eficiente, o mecanismo judicial também possui seu poder de coação. Um juiz deverá tomar suas decisões baseadas nos fatos e no direito, e se o acionista minoritário vier a ser prejudicado por algum interesse majoritário, a par do fator social da empresa, deverá ser dado o ganho de causa para o lado enfraquecido.

\section{Referências}

ABRÃO, Nelson. Da ação revocatória. São Paulo: Universitária de Direito. 1997. p. 27.

BERTOLDI, Marcelo. Acordo de Acionistas. São Paulo: Revista dos Tribunais, 2006.

BORBA, José Edwaldo Tavares. Direito Societário. Rio de Janeiro: Renovar. 8. ed., 2009.

BRASIL. Lei $n^{\circ}$ 6.404, de 11 de janeiro de 1976. Dispõe sobre as Sociedades por Ações. Texto Compilado. Disponível em: <http://www.planalto.gov.br/ccivil_03/ leis/L6404compilada.htm>. Acesso em: 12 set. 2013.

. Lei $\mathrm{n}^{\circ}$ 11.101, de 09 de fevereiro de 2005. Regula a recuperação judicial, a extrajudicial e a falência do empresário e da sociedade empresária. Disponível em: <http://www.planalto.gov.br/ccivil_03/_ato2004-2006/2005/lei/ 111101.htm>. Acesso em: 30 set. 2013.

- Poder Judiciário do Estado do Rio de Janeiro. Assessoria de Imprensa. Rio de Janeiro. Publicada em 11 jul.2013. Disponível em: <http://www.tjrj.jus. br/web/guest/home/-/noticias/visualizar/130708>. Acesso em 14 set. 2013.

- Tribunal de Justiça do Estado de São Paulo. Agravo de Instrumento ${ }^{\circ}$ 1451734120128260000-SP (0145173-41.2012.8.26.0000). Agravante: CONSTRUTORA CONSTERP LTDA. Agravado: ANTONIO AMERICO TAMAROZZI. Relator: José Reynaldo. São Paulo, 04 de dezembro de 2012. Lex: Disponível em: <http://tj-sp.jusbrasil.com.br/jurisprudencia/22796572/agravo-de-instrumento-ag-1451734120128260000-sp-0145173-4120128260000-tjsp>. 
Acesso em 16 set. 2013.

CARVAlHOSA, Modesto. Acordo de Acionistas, São Paulo: Saraiva, 2011.

COELHO, Fabio Ulhoa. Curso de Direito Comercial. Volume 2. São Paulo: Saraiva, $12^{\circ}$ edição, 2010.

COMPARATO, Fábio Konder. 0 poder de controle na sociedade anônima. $3^{\mathrm{a}}$ ed. rev., atual. e corr. Rio de Janeiro: Forense, 1983.

GORGA, Erica. A cultura brasileira como fator determinante na governança corporativa e no desenvolvimento do mercado de capitais. Revista de Administração - USP, São Paulo, vol. 39, 2004.

SCHIMIDT, Dominique. Les Droits de la Minorité dans la Societé Anonyme. Paris: Sirey. 1970.

VIVANTE, Cesare. Trattato di Diritto Commerciale. Milano: Casa Editrice Dottor Francisco Vallardi. 1904.

Artigo recebido em: 20.11.2013

Revisado em: 19.12.2013

Aprovado em: 05.01.2014 